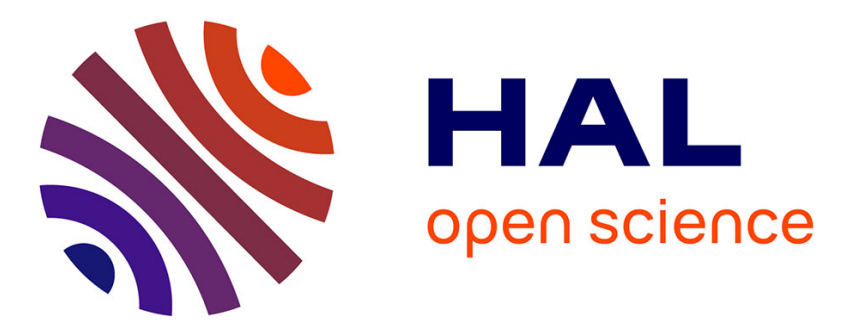

\title{
Morphological diversity and regionalisation of kites in the Middle East and Central Asia
}

\author{
Olivier Barge, Jacques Brochier, Rémy Crassard
}

\section{To cite this version:}

Olivier Barge, Jacques Brochier, Rémy Crassard. Morphological diversity and regionalisation of kites in the Middle East and Central Asia. Arabian Archaeology and Epigraphy, 2015, 26, pp.162-176. 10.1111/aae.12056 . hal-01829324

\section{HAL Id: hal-01829324 https://hal.science/hal-01829324}

Submitted on 4 Jul 2018

HAL is a multi-disciplinary open access archive for the deposit and dissemination of scientific research documents, whether they are published or not. The documents may come from teaching and research institutions in France or abroad, or from public or private research centers.
L'archive ouverte pluridisciplinaire HAL, est destinée au dépôt et à la diffusion de documents scientifiques de niveau recherche, publiés ou non, émanant des établissements d'enseignement et de recherche français ou étrangers, des laboratoires publics ou privés. 


\section{Morphological diversity and regionalisation of kites in the Middle East and Central Asia}

In the last few years, the number of inventoried kites has increased fivefold, and the known distribution zone has been greatly extended across the Near East, Arabia, the Caucasus and Central Asia. High-resolution satellite images provide substantial amounts of data that can be subjected to geomatics analysis. The resulting spatial data is used to identify regional differences. We present here a study of these kite structures at the global, regional and local scales, carried out by means of GIS. The recognition of a number of morphological characteristics, without any subjective attribute, leads to a geographically referenced inventory that clearly distinguishes five main regions. This paper suggests a method to define the morphology of the kites, which will be further augmented with cross-variables including the surrounding environment, settlement distribution, animal exploitation and ethology, providing a base for future studies.

Keywords: desert kites, GIS, typology, Hot Spot analysis, Middle East, Central Asia

\author{
Olivier Barge ${ }^{1}$, Jacques Élie \\ Brochier $^{2}$, Rémy Crassard ${ }^{1}$ \\ ${ }^{1}$ CNRS, UMR 5133, Archéorient, \\ Maison de l'Orient et de la \\ Méditerranée, 7 rue Raulin, \\ 69007, Lyon, France \\ ${ }^{2}$ Aix-Marseille Université \\ (AMU), CNRS, UMR 7269, \\ LAMPEA, Maison \\ Méditerranéenne des Sciences de \\ l'Homme, 5 rue du Château de \\ l'Horloge, BP 647, 13094, \\ Aix-en-Provence, France \\ e-mails: olivier.barge@mom.fr \\ jacques.brochier@univ-amu.fr \\ remy.crassard@mom.fr
}

\section{Introduction}

Desert kites (also simply called kites) have been recorded at a spectacular rate in the last few years, extending both their number and area of diffusion. New regions, sometimes very densely occupied, have been discovered and surveyed in the recent past. In the mid-1990s, the number of estimated kites was a few hundred (Échallier \& Braemer 1995). Now this body of evidence has been recently assessed as approaching 3000 (Kennedy 2012), while the inventory mentioned below, although provisional, includes more than 4500 of these structures (see www.globalkites.fr for a regularly updated interactive distribution map). While some discoveries were made through fieldwork and surveying (Brochier et al. 2014), the majority are the result of research derived from high-resolution satellite imagery (e.g. Kennedy 2012; Barge et al. 2013; Kempe \& al-Malabeh 2013), the study of which was largely favoured by easy online access (Google Earth, Bing Maps). This enlarged body of material revived scholars' interest in these constructions, the age and function of which remain fundamental issues without any satisfactory answers. It appears today that kites and their distribution represent a phenomenon the magnitude of which (Crassard et al. 2014) was until now wholly underestimated.

A new set of questions should be asked, including those relevant to the meaning of concentration zones (these are sometimes isolated), and of areas with lower density and substantial gaps. Likewise, there is great variability in the shape and size of enclosures, number of cells, length of antennae, etc. These can probably be explained by a convergence of different, non-exclusive factors: adjustments to topography, adaptation to function and to species concerned, chronological changes or even cultural traits and characteristics. Research in the field can address questions regarding use and, more importantly, age that have so far remained unanswered due to insufficient and narrowly focused research. They are therefore still badly represented in relation to the vastness of the known area of distribution of kites in the Middle East and Central Asia. Moreover, data now available suggest that kites are a phenomenon that spread over a longue durée, lasting millennia (e.g. Zeder et al. 2013: table 1). We therefore find ourselves confronted with a phenomenon combining a large geographical extension, strong spatial variability and a long 
Table 1. Characteristic features used for each group of kites. The characteristic features relevant in the case of each group are those for which the Getis-Ord Gi* index showed values which were significantly high or low. In other words, the aggregates determined by the Getis-Ord Gi* index, which overlapped spatially, allowed the selection of characteristic features used. Threshold values were adjusted in order best to identify each of these groups.

\begin{tabular}{|ll|}
\hline Groups & Characteristic features \\
\hline G1 & Number of antennae $>1$ \\
& Average length of antennae $>1132 \mathrm{~m}$ \\
& Number of cells $>7$ \\
& Funnel entrance $=$ none \\
& Surface area of the enclosure $<0.9$ ha \\
& Entrance width $<14 \mathrm{~m}$ \\
& Funnel entrance $=$ none \\
& Average length of antennae $\leq 1264 \mathrm{~m}$ \\
G3 & Number of pointed cells $<33$ \\
& Funnel entrance = present \\
& Funnels in antennae = present \\
G4 & Surface area of the enclosure $>1.66$ ha \\
& Complexity Index $>4.74$ \\
& Number of cells $>5$ \\
G5 & Proportion of proximal cells $>46 \%$ \\
& Surface area of the enclosure $>1.18$ ha \\
& Number of cells $<5$ \\
& Proportion of proximal cells $>46 \%$ \\
& Number of antennae $<3$ \\
\hline
\end{tabular}

time frame. By contrast, nothing indicates that practices relating to kites and their intended uses (still largely unknown) remained identical over such a wide area and during several millennia of use.

In order to deal with this phenomenon in its entirety (and follow a holistic approach), it is necessary to trace precisely the geographical distribution of kites, and to provide information on the extreme diversity of their shapes, sizes and locations in relation to the environmental contexts they are associated with. The classification and regional ordering of kites allows the replacing of field studiesnecessarily limited in space - in context, and to assess the extent to which they are representative. This approach has already been pursued by Échallier and Braemer (1995), who used a typological tool for regional comparisons. The corpus thus defined, which was less comprehensive, only took into account Harrat al-Shaam (eastern Jordan) and central Syria, and was restricted to a classification of shapes and to the measurement of the orientations of kite openings. Quite clear tendencies were then revealed. While nowadays we have at our disposal an expanded and much more easily manageable record, this paper is an opportunity to provide details from new studies on kite morphology, enabling us to put forward a regional classification including several groups within the kites' areas of distribution in the Middle East and Central Asia.

Today, online access to high-resolution images offers almost complete coverage, at least in relation to the Middle Eastern areas where kites are found. These documents, however, do not enable scholars to have a comprehensive body of evidence. Field observations have in fact shown that the less preserved kites are not visible on these pictures. By combining repeated field research with the study of satellite images, however, one can not only identify kites but also establish a list of measures and qualifying terms (see below). The analysis of this set of parameters appears to be more reliable and richer in data than typological approaches alone. Those that previously existed were neither systematically ordered nor were they subjected to hierarchical classification. Attempts to order these structures typologically have led often to quite complex classifications, and even then have not made it possible to treat the kite phenomenon in its entirety. The choice of a typology by principle does not guarantee that the new terms and modes of analysis are relevant. For instance, previous typologies were mainly based on the shape of the enclosure (Helms \& Betts 1987; Échallier \& Braemer 1995). Finally, a typology resting essentially on the shape criterion cannot simultaneously take into account size or other characteristics, such as cell distribution around the enclosure or even certain entrance configurations.

In order to mitigate the effects of those biases, it is therefore of paramount importance that separate descriptive terms be used. The geographical distribution of these descriptive terms can then be analysed, either individually or as recurrent associations. It is thus possible retrospectively to create typologies, which are no longer built from supposedly relevant clues (e.g. form), but from the association of discrete traits in space and/or time. Such an approach allows a better understanding of the complete diversity encountered so far.

The aim of this article is to suggest a regional classification of kites based on discrete descriptive criteria. This regional ordering therefore relies on the dominant characteristics of kites, which are elements of the various areas under focus. What is attempted is an initial spatial ordering, allowing one to replace the results of field approaches, to recontextualize them and assess their impact and significance. This approach therefore prevents interpretations originating from isolated cases from being applied to the whole set of data belonging to kite distribution areas.

We shall first present the points that lead to a new definition of kites on which this study is based. The descrip- 
tion of the qualitative and quantitative traits of the kites will be then presented, before dealing with several series of analyses carried out on data from the corpus of evidence: the spatial ordering of traits and the analysis of clusters. Finally, a regional classification of kites (in five distinct groups) for the entire area of distribution will be proposed.

\section{Defining a kite and the corpus of evidence under study}

The principle of walls, or guiding lines, converging to form an enclosed space is common throughout the world, since such structures are known in both North and South America and in Scandinavia, both on land and in aquatic environments. All these constructions are for hunting purposes, which form part of the discussions on the attribution of function to the kites. In the case of kites, however, this function is only rarely proved, and is never detailed in the description of the ways kites were used. The definition of a kite cannot, therefore, be exclusively based on function. This definition should enable to distinguish kites from other structures with converging walls. The observation of the kites' architectural peculiarities allows one to do so without necessarily involving geographical distinctions. Indeed, eastern kites (from the Middle East and Central Asia) all have in common the presence of small adjacent structures (cells) in the external part of the enclosure, a peculiarity that distinguishes them from other constructions. A kite can hence be defined as follows: 'a construction constituted of long walls or stone lines whose converging extremities delineate the entrance to an enclosed space, which itself shows small cells adjacent to its external periphery.'

A kite should therefore present three characteristics: 1) converging walls (or stone alignments); 2) an enclosed space open at the convergent extremity of the walls; and 3 ) one or several cells (small enclosed and walled spaces) at the external periphery of the enclosed space.

The joint presence of these three characteristics allows us to distinguish Middle Eastern and Central Asian kites from other structures with long walls converging on an enclosure, known elsewhere. The extreme diversity of shapes, sizes and architectural characteristics encountered (all of which are difficult to record and present together in a graphic model) are thus contained in the definition proposed.

Yet the simultaneous presence of three traits can prove to be too restrictive: there are some cases that do not meet all the conditions laid out but that clearly belong to the kite phenomenon. For reasons linked to the local topographical configuration or to conservation, some kites can have only one antenna, or even no antenna at all. For the same reasons, the enclosed space may only be partly built. This is especially true in the case of kites located along the Ustyurt Plateau (Chink), where an impassable escarpment acts as a wall in the site's general architectural layout (Barge et al., in press). There are also rare cases (less than $1 \%$ of the total recorded kites) that have no cells at all. These kites are located close to others that strictly meet the definition given above. This proximity then becomes a criterion that enables us reasonably to include them in the corpus. Taking into account the relative proximity of kites is incidentally the way an informed observer's mind works: there are kites which show peculiarities but whose set of elements and presence within a group induce the scholar to integrate them into the corpus.

These three morphological criteria, when necessary completed by the proximity criterion, therefore enable a better definition of the kite.

Some constructions are nevertheless excluded from this definition, even though a number of these are usually considered to be kites. Among these, the 'kites' of Yemen and of Negev/Sinai and the crescent-shape constructions on Kazakhstan/Uzbekistan's Ustyurt Plateau should be highlighted.

To begin with, Yemen's 'kites' are constructions that show two converging walls. The latter, however, do not end in an enclosed space. Moreover they do not contain cells, while there are several small parallel walls, perpendicular to the long converging walls (Brunner 2008). These differences lead one to suppose that the functional modes and layout of the construction are different from those of a kite and therefore that the functions of these man-made structures could themselves be different. Finally, the proximity criterion cannot be applied, since Yemen's 'kites' are more than $1000 \mathrm{~km}$ from those of the Khaybar region, which belong to the Hijāz group (in Saudi Arabia).

As for the Negev/Sinai kites, they are structures in which the long walls do not really converge into an enclosed space but meet at a pit. Cells are absent from the structure. The analogy with kites is merely in the general layout. This analogy is only valid if one accepts the scale factor as irrelevant, as the ditch measures only a few square metres, while the smallest kites possess enclosures of several hundred square metres, the average being 


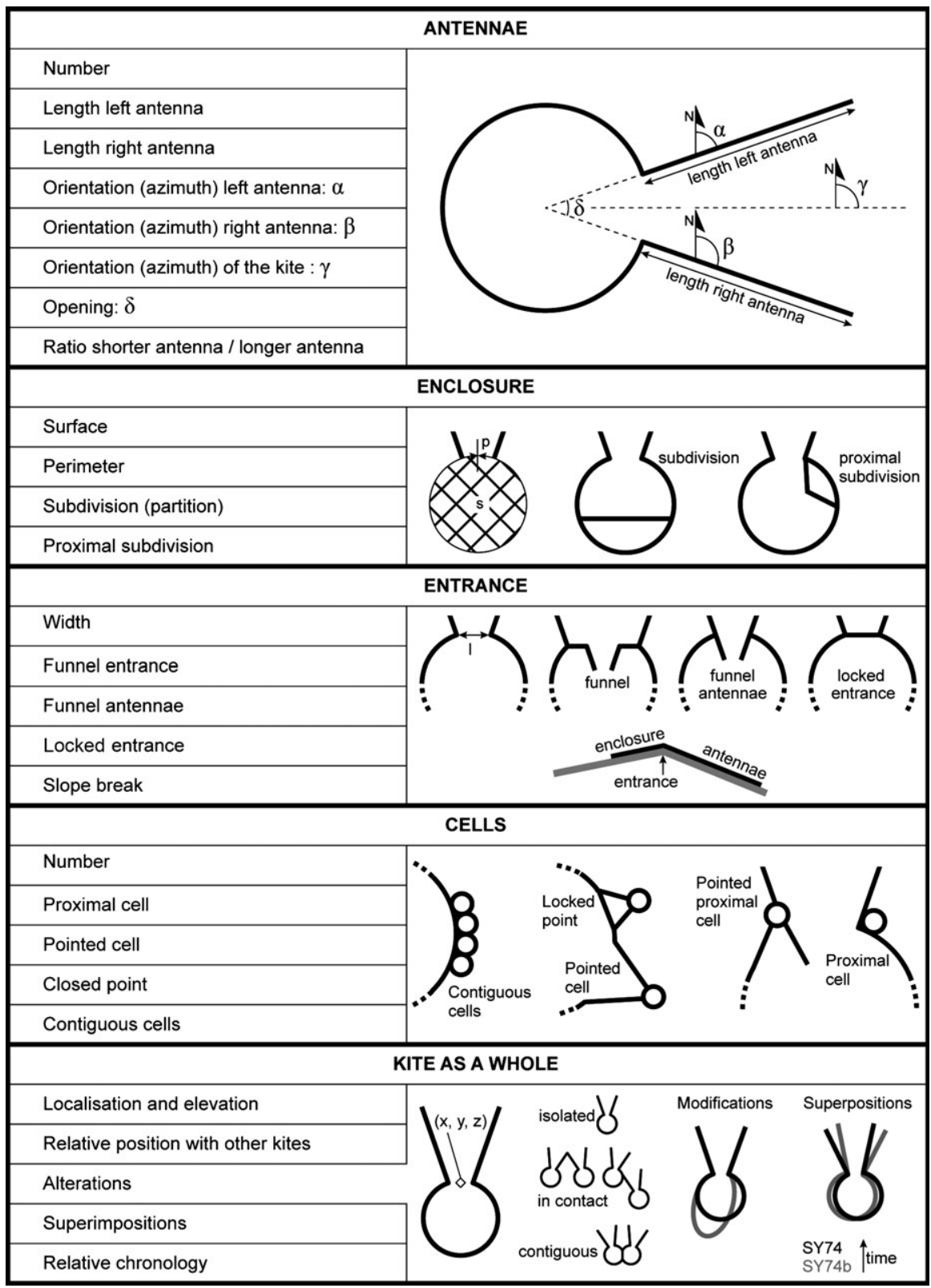

Fig. 1.

The constituent elements in the morphology of kites.

1.7 ha. When drawn on the same scale, the Negev's kites could be compared to the pointed cells noticed at several sites. Moreover, these constructions are relatively scarce (about twenty of them exist), while the proximity criterion remains of very slight or at least of very relative importance, since the Negev kites are located more than $200 \mathrm{~km}$ from the closest group. The paradox is that the Negev 'kites' were studied in particular detail (Holzer et al. 2010; Nadel et al. 2010, 2013), certainly more closely than all other kites, so that reliable chronological indica- tions and satisfactory functional interpretations for the former are available in the literature.

Yet without even looking at the size factor, morphological criteria neatly set kites apart from the structures discussed above. It is therefore a mistake to extend chronological and functional interpretations concerning the issue of Negev/Sinai kites to the set of Middle Eastern and Central Asian ones.

Finally, the Ustyurt Plateau's crescent-shaped constructions are structures that form chains, all oriented in a simi- 


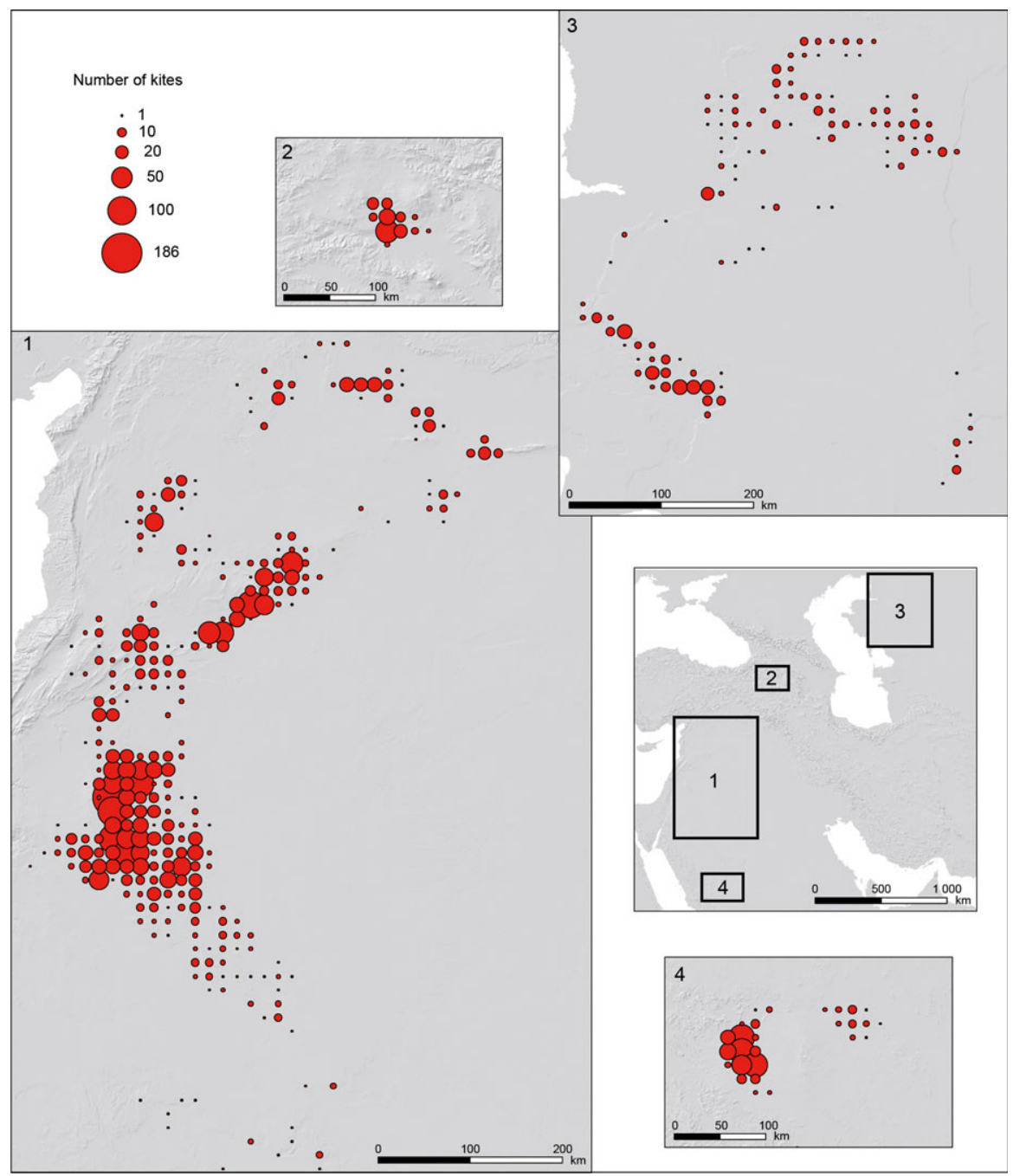

Fig. 2.

The number of kites per mesh (totality of the corpus). From north to south, four windows were studied: Ustyurt Plateau (Kazakhstan and Uzbekistan); Armenia; the central zone from the Taurus foothills to the margins of the Nefud Desert; the Khaybar area in the Hijāz region (Saudi Arabia).

lar direction. They are distributed in a peculiar way on the plateau's surface, often at the edge of closed corridors between marshy areas. Kites have also been recorded on the plateau itself. Their location, their disposal within a chain and their orientations are analogous, which leads to the possibility of a functional analogy as well (Barge et al., in press). Nevertheless, these crescent-shaped constructions are, from a morphological viewpoint, very different from kites.

The discussion of these three types of construction will hence be excluded from our paper, even though one could suggest points that support their classification as kites. The intention is not here to attribute - or not - the 'kite' label, but more narrowly to define the object of our study, since the variability to be taken into account is already quite considerable. In any case, the inventory and study of these structures are already of evident interest, and the analysis of analogies and differences can also be quite didactic and itself yield much information.

\section{The morphology of a kite: nomenclature}

The definition proposed relates four constituent elements of the kite: the long converging antennae, the enclosed space, the entrance and the cells. Each of these elements could be the object of a number of measurements or qualitative descriptions (Fig. 1). It is necessary to define here the terminology used, since several different terms could designate the same elements in the archaeological literature. 


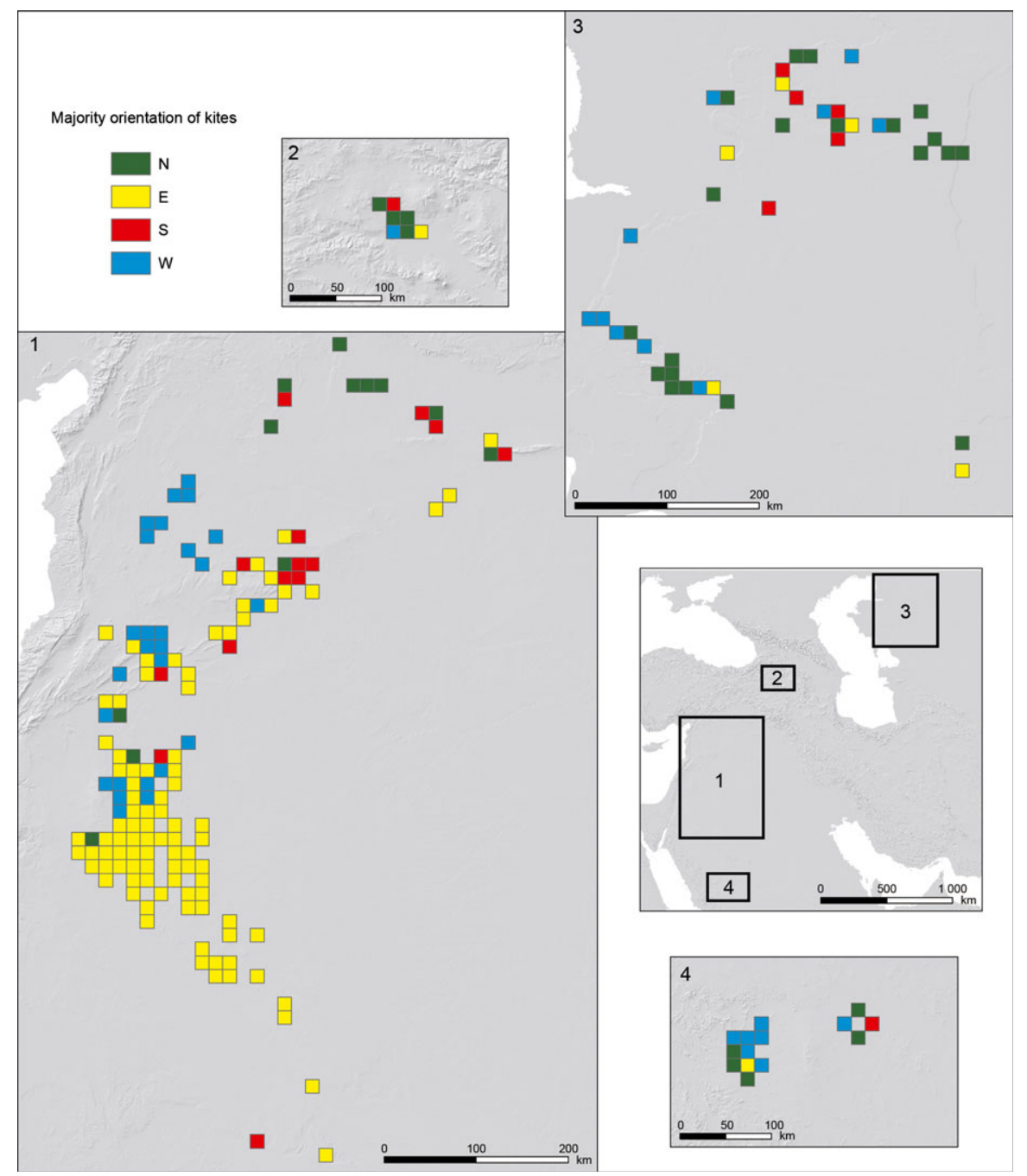

Fig. 3.

The main orientation of kites.

\section{The antennae}

The long converging walls, or mostly just lines of stones as they are too low to be described as walls, are sometimes designated by the term 'guiding walls', which is for us quite inappropriate, since theoretically this expression infers a function. Other terms used are 'arms' or 'antennae'. The latter will be the one used in descriptions of kites here.

Although the majority of kites show two antennae, there are cases where only one or none is apparent. The opposite situation also exists, since kites with more than two have been recorded, the number of antennae reaching at times half a dozen. The number of antennae therefore constitutes the first major relevant trait. Each of these antennae has been subjected to a measurement of its length and a study of its orientation. From these measurements, it is possible to calculate several variables: the mean length of antennae; the asymmetry (the ratio of the shortest length to the longest, expressed in percentages); the kite's orientation, which corresponds to the bisecting line of orientations of both antennae; and the opening, which is the angle formed by the two antennae. Orientations are measured from the inside towards the outside, and directions mentioned in the next pages of the article should be understood in this way.

\section{The enclosure}

The term 'corral' is sometimes found in the literature to designate the space enclosed within the antennae's extremity. As 'corral' infers a function, here we prefer to use the term 'enclosure'. 


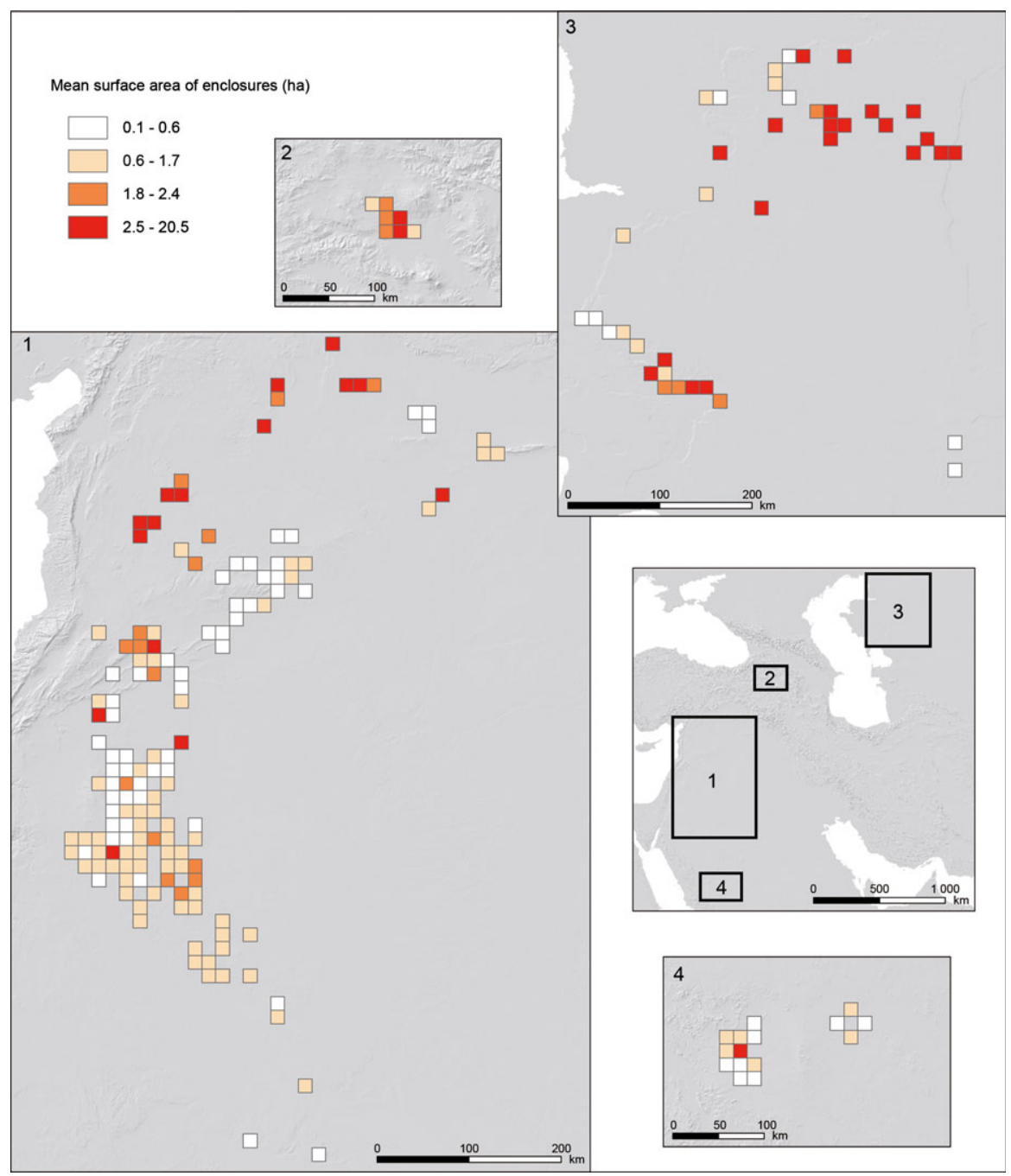

Fig. 4.

The average size of the surface area of the enclosure.

The surface and perimeter are measured by outlining the enclosure and its constituent walls (therefore excluding cells), and by virtually extending them at entrance level.

The enclosure's shape has often been used as a distinctive element and it is from its very shape that Échallier and Braemer (1995) created their typology. Enclosure shapes reminiscent of geometric forms (circles, stars, triangles, etc.) do in fact exist. Nevertheless there are also a large number of irregular shapes unlike any other geometric form, or whose classification remains ambiguous. A Dissection Index - from the surface(s) and the perimeter(s) is estimated by applying the formula $\mathrm{p} / \sqrt{\mathrm{s}}$. This index provides an approach for assessing the complexity of the shape (albeit in a simplified way) but is of interest because the kite's surface and shape can be quantified (e.g. Kempe \& al-Malabeh 2013; Brochier et al. 2014).

Occasionally the enclosure has subdivisions, which also have a tendency to be at a proximal location (i.e. near the entrance). Subdivisions and proximal subdivisions are, in relevant cases, accounted for.

\section{The entrance}

The entrance is the location where, between antennae, the enclosure wall stops, thus allowing access. The width of this space - the entrance - is systematically measured. On frequent occasions it would seem that the kite's location was chosen in a way that enables a break in the slope at the level of the entrance. The presence or absence of a break in the slope was recorded. Furthermore, the entrance 


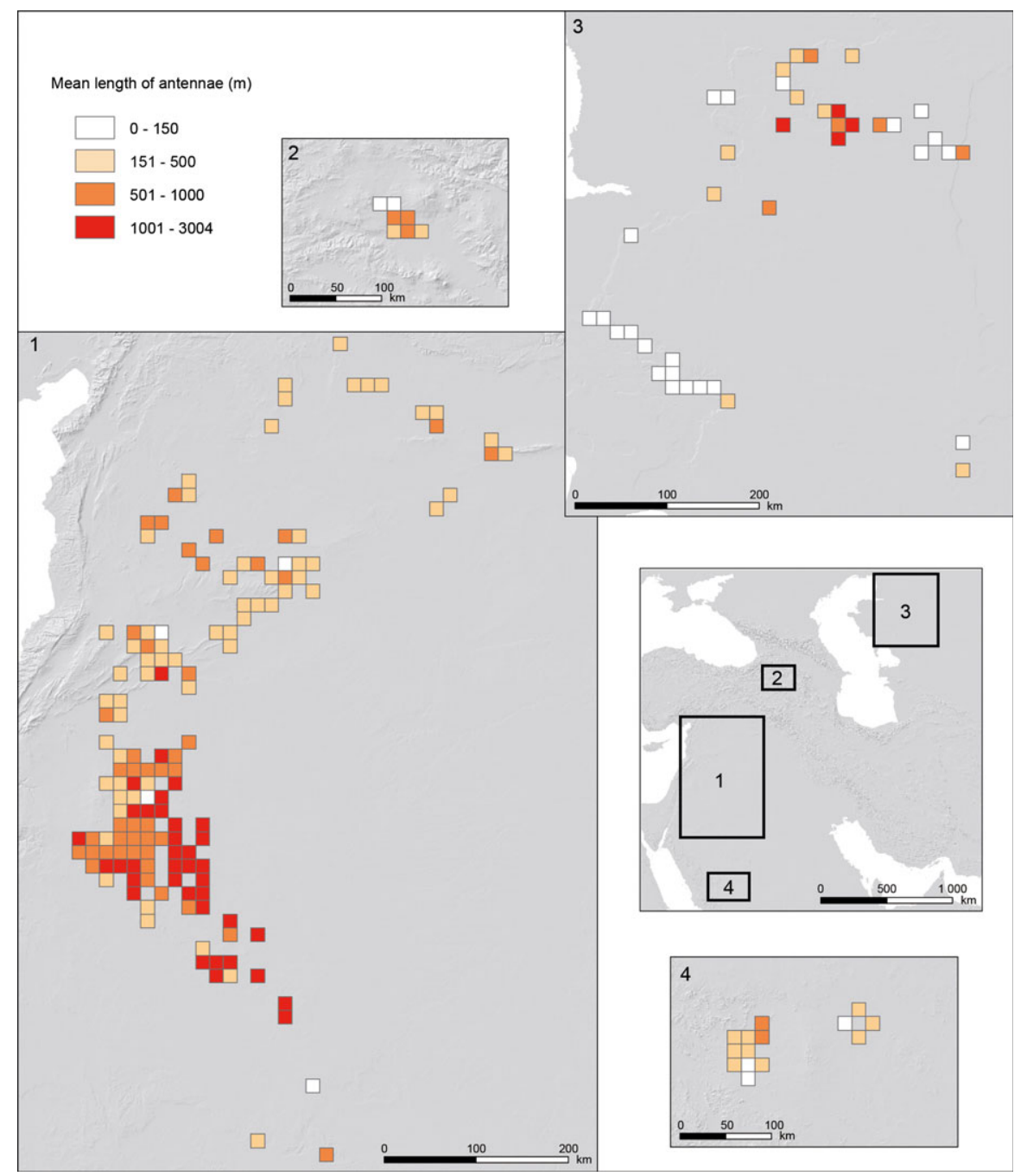

Fig. 5.

The average length of the antennae.

might show relatively frequent morphological peculiarities: it might be bordered by two low walls - symmetrical and converging towards the interior-linked to the enclosure, thus creating a funnelled entrance. When this funnel is made up of the lengthening of the antennae within the enclosure, it is called a funnel antenna. Finally, although this creates a functional problem, it can happen that the enclosure wall continues in the space between the antennae. This forms what has been called a locked entrance.

\section{The cells}

As explained above, the small cells adjacent to the enclosure are what make Middle Eastern and Central Asian kites unique. Although their function, albeit essential for understanding the kite (to judge from their permanent presence and the care involved in their construction), remains enigmatic, they represent an important element of the kite. Previous interpretations of the cells include places for hiding, pits, dwelling structures or domestic spacesall of these are hypothetical. The term 'cell', which has no functional connotation, will be used to name these small constructions. The number of cells is the first datum that can be recorded. The position and shape of some of the cells are important elements in themselves, in that they can partly determine the kite's general shape. Cells are mainly located close to the entrance when they are called proximal cells. Cells built at the extremity of appendices with a pointed shape are also frequent. They are then called pointed cells which, when numerous, turn the kite into a star shape. When these appendices are separated 


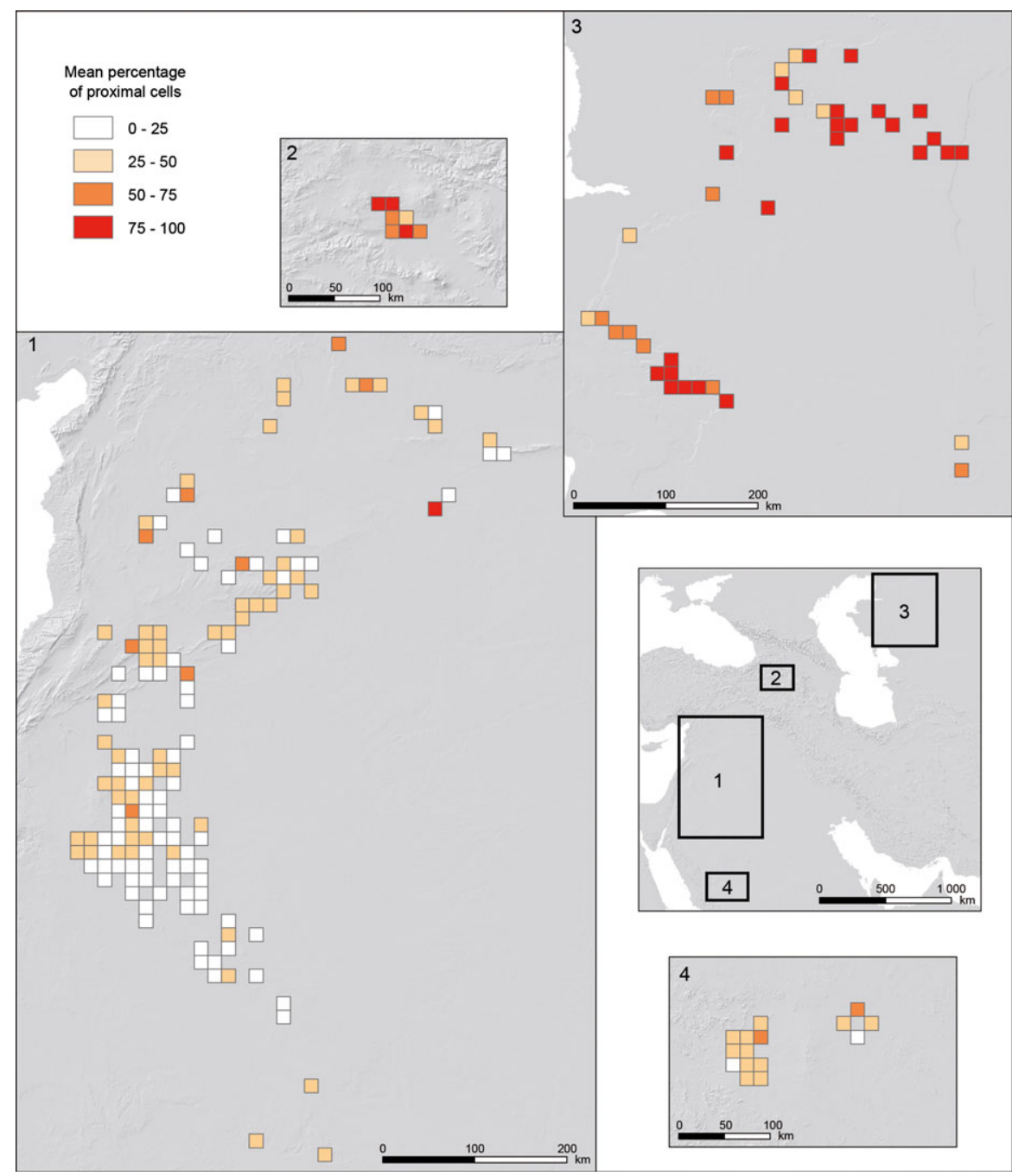

Fig. 6.

The proportion of proximal cells in relation to the total number of cells.

from the enclosure by means of a wall they are called locked points. The number of each of these three types of cells has been recorded. Finally, in some kites, cells are built next to each other in groups of two, three or more. In this case, cells are described as contiguous, and the number of contiguities has been recorded.

\section{The kite as a whole}

A number of characteristics concerning kites taken as a whole were recorded. First of all, the tri-dimensional coordinates $(\mathrm{x}, \mathrm{y}, \mathrm{z})$ locate a kite and are used for small-scale mapping. According to convention, the point representing the kite's location was fixed in the middle of the entrance. Thus, kites can be distributed in relation to others in a specific way. This relative position can be isolated, in contact or contiguous. Alterations in the kite's plan can at times be clearly distinguished, perhaps an indication of their longterm use. Finally, perceptible alterations sometimes involve the entire kite, the latter being entirely rebuilt on the same spot. This superimposition sometimes allows the creation of a relative chronology between two and sometimes even three phases of construction.

For each kite, it is therefore possible to record or calculate twenty-two different characteristic traits, along with the kite's coordinates. Not all traits are of the utmost relevance but some, once mapped, show clear regional peculiarities. Likewise, some associations of features are characteristic of specific regions. The collection of all features, for all 4500 kites, is a huge task. We limited ourselves to the recording of a random sample of 500 kites, a 


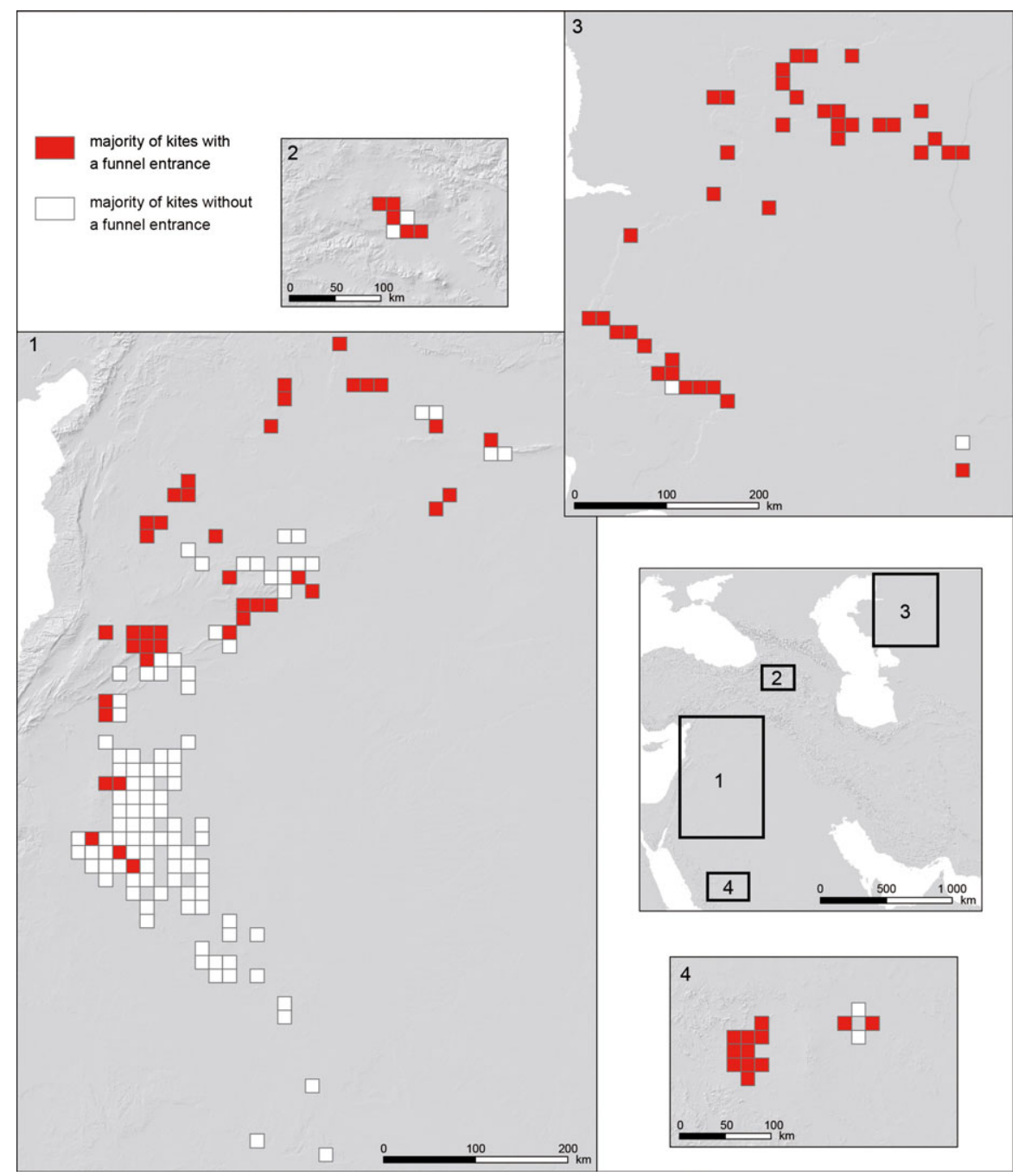

Fig. 7.

Major occurrences of funnel entrances.

little more than $11 \%$ of the total, the distribution of which reflects the general distribution. The premise is that this sample is representative of the corpus as a whole.

\section{Mapping characteristic features and traits}

Within the Geographic Information System (GIS), each kite is represented by a point located by means of coordinates. The set of kites is inscribed in a rectangle measuring approximately $2000 \mathrm{~km}$ from east to west and $2500 \mathrm{~km}$ from north to south. The distribution of these points is neither homogeneous nor random, thus enormous amounts of information are located within clusters, while huge spaces contain no indications. Such a distribution poses a problem in terms of representation: how can one render visible the information contained in the clusters? The first cartographical approach consisted in dividing the area into four 'windows' shown on the same scale so as to 'eliminate' gaps: from north to south, the Ustyurt Plateau, Armenia, the central zone extending from the Taurus foothills to the Nefud desert and the Hijāz's Khaybar region. Even when the space was divided in this way, points were still very close to one another and were often superimposed, mutually hiding the information they contained, leading to erroneous and deceptive representations. In order to avoid any misrepresentation, the second approach was to divide the space in which kites are present into mesh squares $15 \mathrm{~km}$ long, then to combine the information from the subsets of kites present in each mesh square (mean or majority). This method provides a more objective representation, despite 


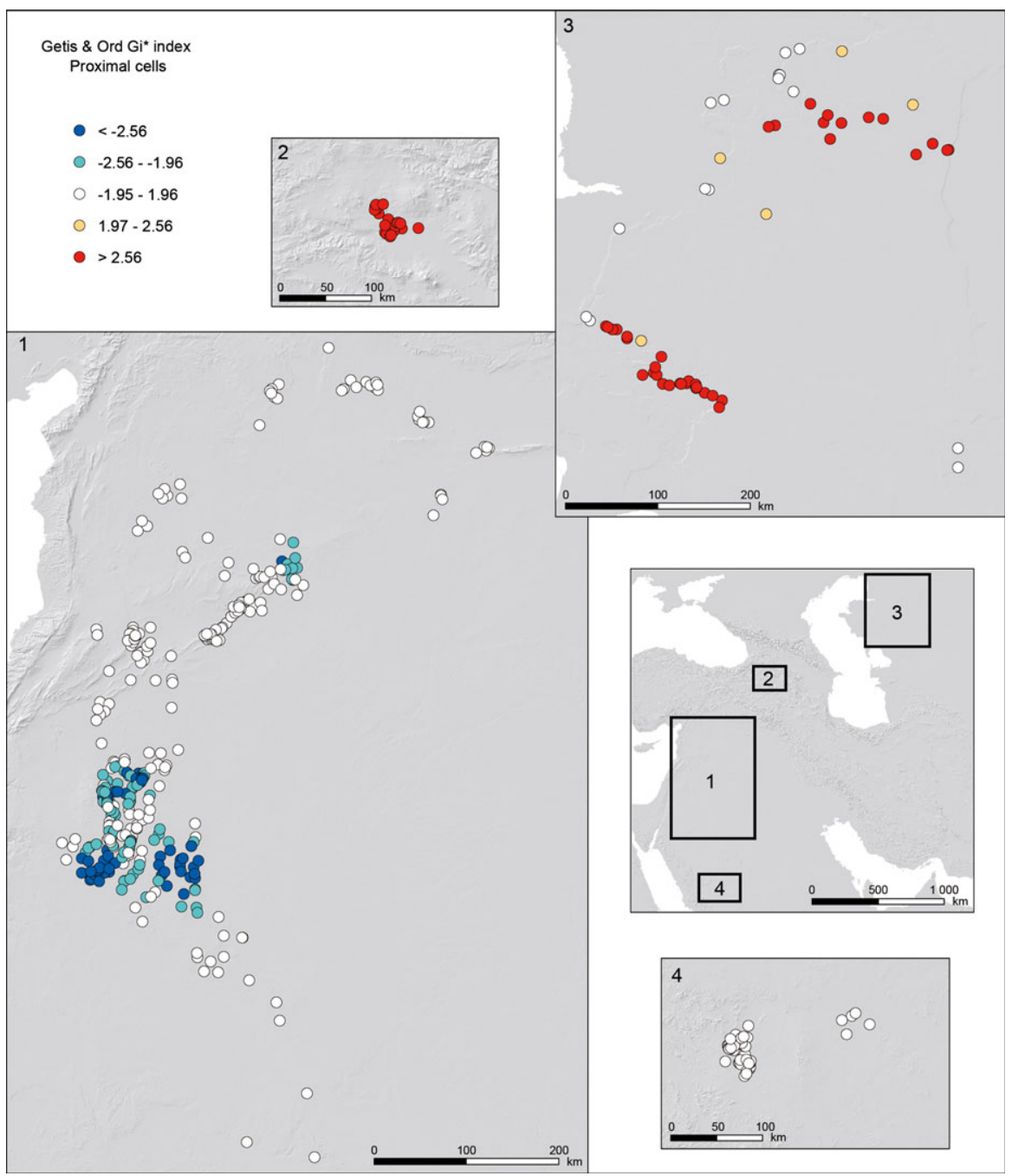

Fig. 8 .

An example of mapping using Hot Spot Analysis (Getis-Ord Gi* statistics): the proportion of proximal cells.

the fact that the mesh's position could correlate the information of a variable number of kites. The size of the mesh was selected in order to minimise this phenomenon while remaining clearly visible at the chosen scale. Only the most distinguishing characteristic features will be shown here: maps were created from a sample of 500 kites, with the exception of the first one, which takes into account the entire body of evidence.

\section{Geographical distribution of kites}

The map showing the number of kites per mesh (Fig. 2) reveals that the highest densities were encountered in the Harrat al-Shaam region between Syria and Jordan. This region of high or medium density is particularly extensive, in comparison to some other areas which show compara- ble density on a much more limited surface: the Palmyrene mountain range, Central Arabia and Armenia.

The map clearly shows that kite distribution is not random. It is not homogeneous either, with the possible exception of the Ustyurt Plateau's northern sector. Kites have a tendency to cluster in large numbers in relatively restricted sectors, with the notable exception of Central Arabia and Armenia. Phenomena such as progressive dispersion from a centre with high concentrations towards the periphery were not noticed, except in Harrat al-Shaam's extension towards northern Arabia.

\section{Orientations}

The map showing orientations (Fig. 3) roughly reveals two types of distribution: the regions in which one finds a 


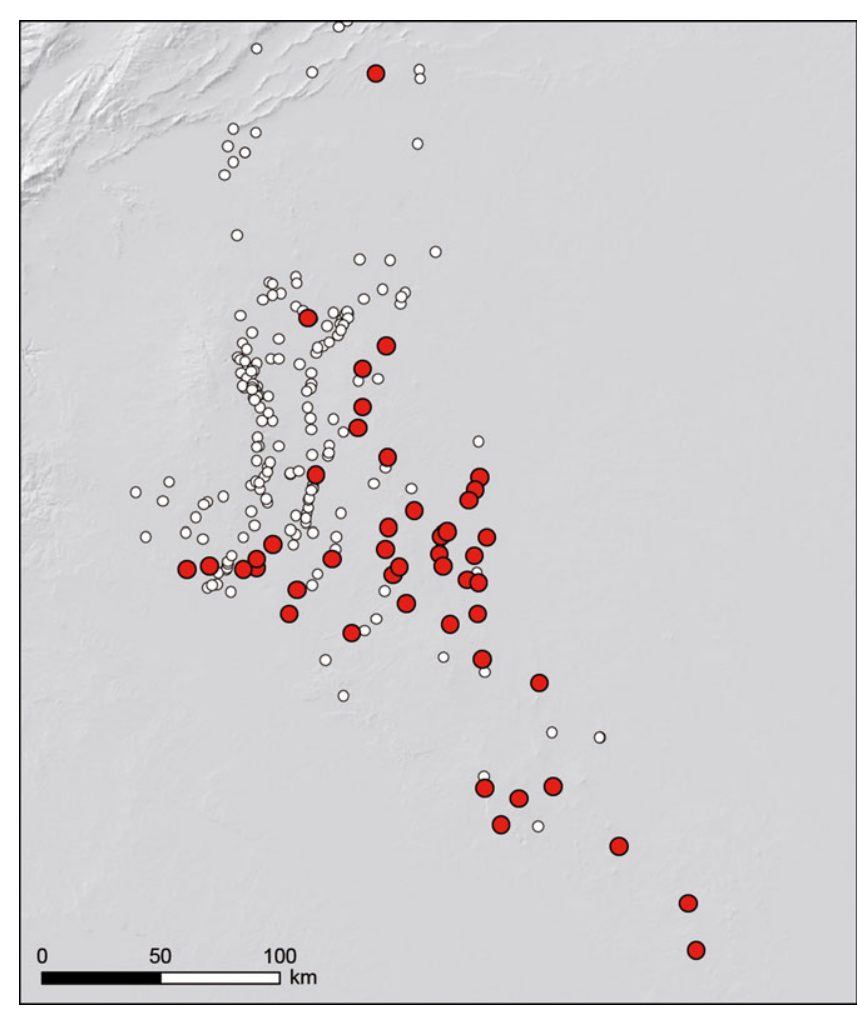

Fig. 9.

The kites from Harrat-al-Shaam: kites from group G1 are in red; other kites are in white.

diversity of orientations, and those in which kites are all oriented in a similar fashion. Among the first group are Armenia, the Taurus foothills (Turkey and north-eastern Syria), the Palmyrene mountain range and the eastern cluster of the Central Arabian zone. In Armenia, it is understood that the diversity of orientations is to be explained by the positioning of kites relative to lava flows (Brochier et al. 2014). It would seem, after preliminary analysis, that this is the case in other regions of this first group. Within the second group, one should mention above all the Harrat al-Shaam zone, where the openings of kites are mostly oriented towards the east, with the exception of this area's north-western fringe where, in contrast, it is oriented towards the west. The predominant orientation towards the west was also noted in the western part of Central Arabia, much more so than is revealed by the map, since the clustering effect in the mesh obscures the regularity of orientations towards the west.

\section{The surface of enclosures}

Figure 4 shows the average size of enclosures for kites belonging to each mesh. In the north of the Ustyurt Plateau, kites are of considerable size. Elsewhere, one finds enclosures of large size in Armenia, in Central Syria - as regards this particular characteristic, reaching the southern Taurus - and to a lesser extent, in the south of Harrat alShaam. By contrast, enclosures appear to be of small size over the entire surface of the Palmyrene range, in the north of Harrat al-Shaam and in Central Arabia.

\section{The length of antennae}

Figure 5 reveals that the longer antennae are essentially found in the Harrat al-Shaam, in particular in its southern part. To a lesser extent they are also found in the northern part of the Ustyurt Plateau.

\section{Proximal cells}

This characteristic (Fig. 6), which consists in placing the cells predominantly near the entrance (often on both sides of it) is witnessed to the north of the distribution area, on the entire Ustyurt Plateau and in Armenia. This particular aspect is much less frequent in Harrat al-Shaam, above all in its southern part.

\section{The funnel-shaped entrance}

This characteristic (Fig. 7) is an almost systematic feature of the Ustyurt Plateau as well as Central Arabia. It is also frequently found in Armenia and in the arch running from Al-Qaryatayn (Qalamoun, Syria) to the Jabal al-Has (south-east of Aleppo), and then to the southern Taurus. Apart from a few exceptions, it is absent from Harrat al-Shaam.

As a general rule, the other characteristics do not reveal a very marked regionalism on the general scale of the distribution area, even if there are at times interesting peculiarities. The mapping of these characteristic traits will not be presented here. The interpretation of other maps shows that certain regional characteristics tend to be repetitive from one characteristic trait to another, in a way that enables a fairly neat overview of the various different sets of kites.

\section{Revealing homogeneous regions}

Several characteristic traits, however, do show marked regionalism. Another way of tracing these regional markers is to compute, for quantitative variables, a local index of spatial self-correlation (Hot Spot Analysis, Getis-Ord Gi* statistics), of which an example is shown here, together with a presentation of the proportion of proximal cells (Fig. 8). This index enables the pinpointing of spatial clusters and the correlation of the distribution of the rela- 


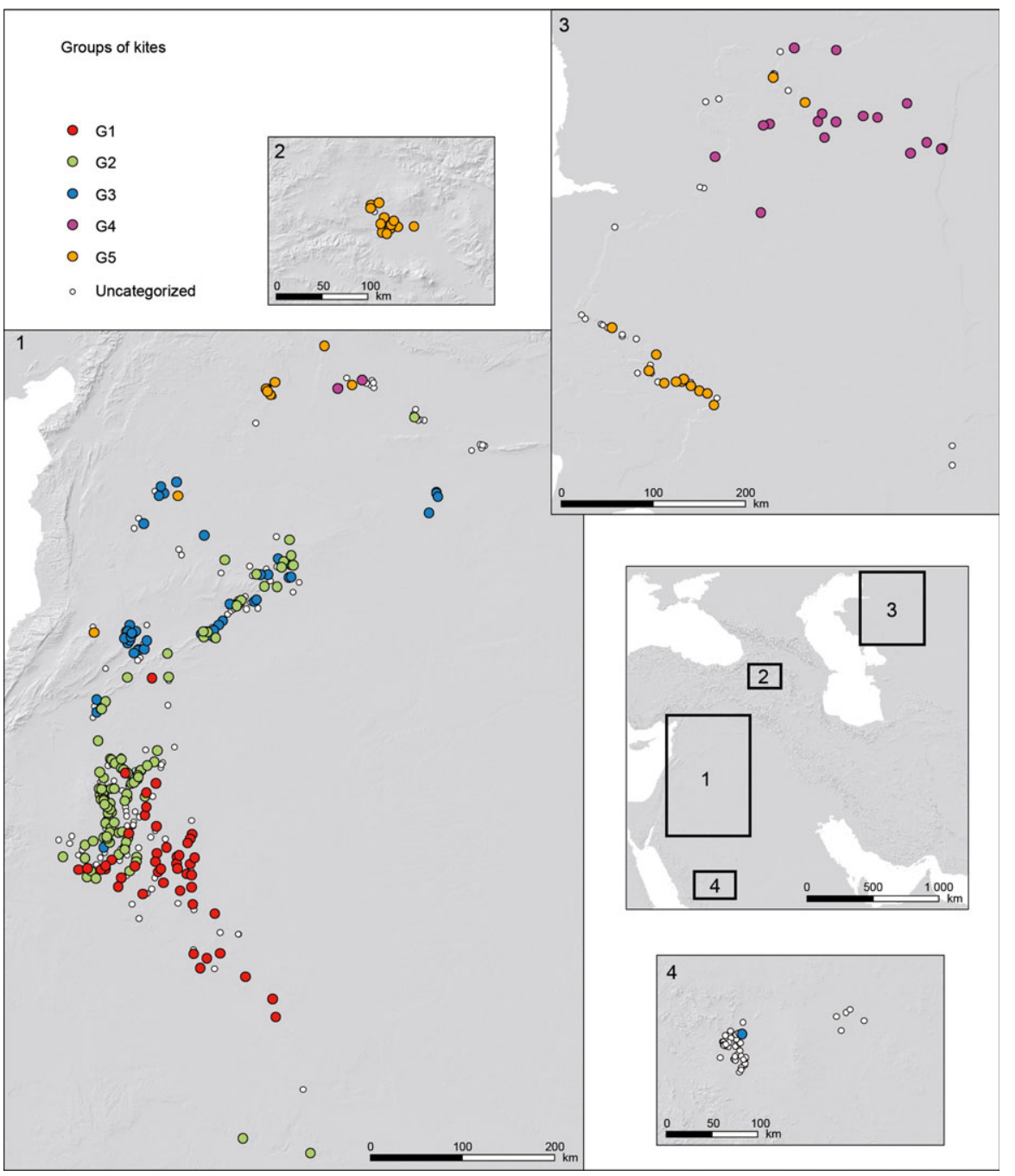

Fig. 10 .

The geographical distribution of groups G1, G2, G3, G4 and G5.

tive values of characteristic traits (Zaninetti 2005). Mapping this index leads to the same observations as examining the cartography of the characteristic trait, and also enables the identification of (negative or positive) clusters from an objective standpoint.

By outlining the clusters for each characteristic feature, it is then easy to trace the regions that show significantly low or high values for several characteristic features. For instance, the Getis-Ord Gi* index maps of each characteristic feature show that, in the south-eastern part of Harrat al-Shaam, kites tend to have a large number of very long antennae and many cells, and do not have a funnel-shaped entrance. In fact, when a classification of all kites into two sets is made (i.e. those that jointly show these characteristics [ $\mathrm{n}=47]$ and those that do not $[\mathrm{n}=453])$ a map can be traced (Fig. 9). Its extension does not go beyond Harrat alShaam, and related kites are found in the south-eastern half. Needless to say, not all kites of this sector's sample were ordered and classified (the majority, but not the entire group). It is nevertheless possible to state that, in the southeast of Harrat al-Shaam, the majority of kites show a set of characteristic features typical and unique to the region.

This operation was carried out on five occasions, corresponding to the five regions showing an association of at least three characteristic features, the values of which are spatially clustered in a significant way.

Five groups have been outlined (all kites belong to one group only). These groups are quite well outlined spatially, and their distribution can be classified as follows (Fig. 10): 


\section{MORPHOLOGICAL DIVERSITY AND REGIONALISATION OF KITES}

G1: as we have seen, these kites are typical of Harrat al-Shaam's south-eastern part;

G2: these small kites (short antennae, small enclosed surface and narrow entrance), without a funnelshaped entrance, are located in Harrat al-Shaam's north-western half and in the Palmyrene range. Some are also disseminated between these two regions;

G3: these kites with few pointed cells and funnelshaped antennas are spread over the entire area of Al-Qaryatayn and the Jabal al-Has. They are also found - albeit not exclusively - in the Palmyrene mountain range;

G4: these complex kites with a large enclosure, many cells, a considerable number of which are in a proximal position, lie to the north of the Ustyurt Plateau, essentially on the plateau itself;

G5: these kites with a relatively large enclosure but with few cells (mostly in proximal position), are typical of Armenia and often appear along the Ustyurt's south-western chink. To a lesser extent, they are also found to the south of the Taurus.

\section{Conclusion}

This first typological and statistical GIS analysis of characteristic features shows that it is possible regionally to classify and map the distribution area as a whole, with the exception of the Hijāz, for which no association of marked characteristic features could be defined (Fig. 11).

The enormous concentration in Harrat al-Shaam shows two groups of kites with very different characteristics; one group lies in the south-western half and another in the north-western one. A thin bisecting band in the middle reveals the co-existence of these two types of kites. The west of central-western Syria (Al-Qaryatayn, Jabal al-Has) is a homogeneous area, with kites whose characteristics are nevertheless also found in the lower Jazirah and the Palmyrene mountain range. The latter is made up of comparable proportions of kites typical of, on the one hand, central-west Syria and, on the other, of north-west Harrat al-Shaam. Kites of the northern part of the Ustyurt Plateau's surface (kites with a double arrow) can be neatly isolated and distinguished from the rest. This is also the case of kites on the plateau's edge, particularly along the south-western chink. The latter share characteristics similar to Armenia's kites, characteristics also shared by those to the south of the Taurus Mountains (Barge, Brochier \& Karakhanyan, in press).

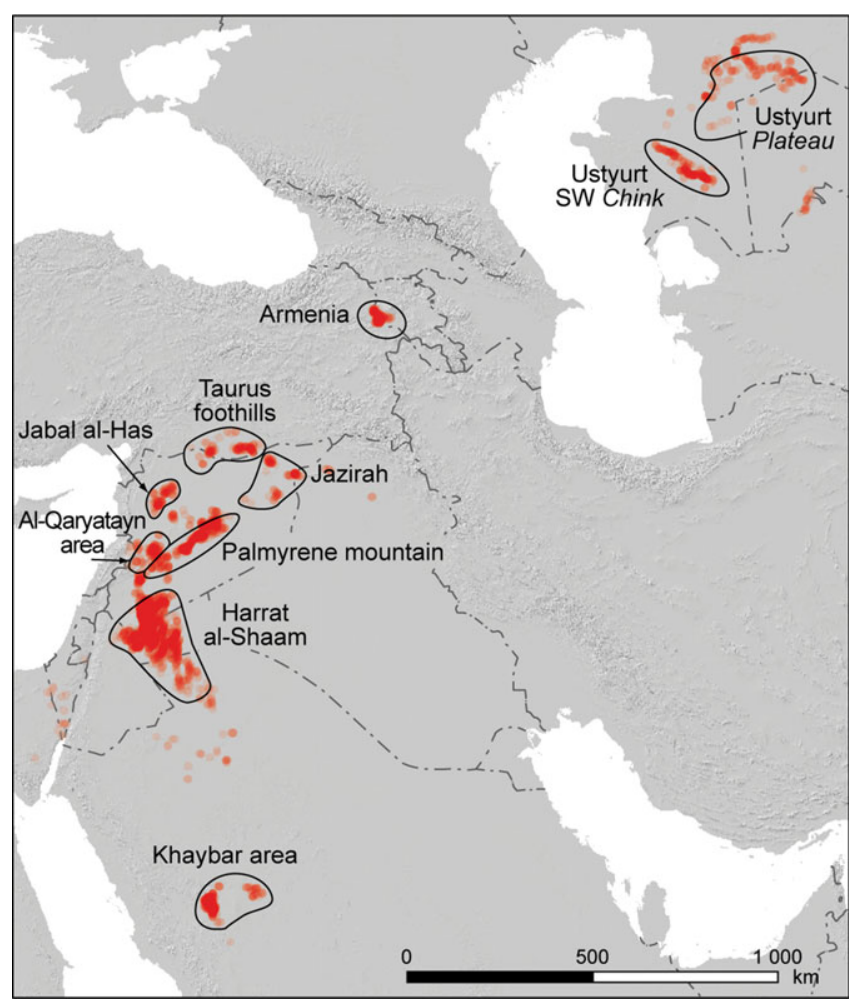

Fig. 11.

The main regional groups suggested by the association of characteristic features.

The aim of this study was to regroup kites in regions where they showed homogeneous morphological characteristics. The results published in this paper are those of the first analyses, which only make use of some of the characteristic features; other methods of analysis are in their initial stages of development. These preliminary results are nevertheless satisfactory and should allow the channelling of future research in the field with a comparative perspective in mind. The fundamental issues of function, chronology and meaning of these geographical distributions are still awaiting further study. Deeper involvement in the field will therefore be crucial in order to address these different questions. Complementary approaches such as zooarchaeology and animal ethology will also prove to be essential (Chahoud, Vila \& Crassard, this volume).

\section{Acknowledgements}

This research is being conducted by the Globalkites ANR project (funded by the Agence Nationale de la Recherche ANR, France (2013-2017, No. ANR-12-JSH3-0004-01, to R. Crassard). We would like to thank Ueli Brunner for inviting us to present our preliminary results at the 2014 ICAANE conference in Basel, and to contribute to this special issue. 


\section{O. BARGE ET AL.}

\section{References}

Barge, O., Brochier, J.É., Karakhanyan, A. in press. Northernmost kites? Quaternary International.

Barge, O., Brochier, J.É., Chahoud, J., Chataigner, C. et al. 2013. Towards a new approach to the 'kites phenomenon' in the Old World: the GLOBALKITES Project. Antiquity 87/338, Project Gallery. Available at http://antiquity.ac.uk/projgall/ barge338/ [Accessed 19 March 2015].

Barge, O., Brochier, J.É., Deom, J.-M., Sala, R. et al. in press. The 'desert kites' of the Ustyurt plateau. Quaternary International.

Brochier, J.É., Barge, O., Karakhanyan, A., Kalatarian, I. et al. 2014. Kites on the margins. The Aragats kites in Armenia. Paléorient 40/1: 25-53.

Brunner, U. 2008. Les pièges de chasse antiques au Yémen. Chroniques yéménites 15: 29-34.

Chahoud, J., Vila, E. \& Crassard, R. this volume 2015. A zooarchaeological approach to understanding desert kites. Arabian Archaeology and Epigraphy 26/2.
Crassard, R., Barge, O., Bichot, C.-E., Brochier, J.É. et al. 2014. Addressing the Desert Kites Phenomenon and Its Global Range Through a Multi-proxy Approach. Journal of Archaeological Method and Theory. doi: 10.1007/ s10816-014-9218-7.

Échallier, J.-C \& Braemer, F. 1995. Nature et fonction des 'Desert Kites': données et hypothèses nouvelles. Paléorient 21/1: 35-63.

Helms, S. \& Betts, A.V.G. 1987. The Desert 'Kites' of the Badiyat Esh-Sham and North Arabia. Paléorient 13/1: 41-67.

Holzer, A., Avner, U., Porat, N. \& Horwitz, L.K. 2010. Desert kites in the Negev desert and northeast Sinai: their function, chronology and ecology. Journal of Arid Environments 74/7: 806-817.

Kempe, S. \& al-Malabeh, A. 2013. Desert kites in Jordan and Saudi Arabia: structure, statistics and function, a Google Earth study. Quaternary International 297: 126-146.
Kennedy, D. 2012. Kites - new discoveries and a new type. Arabian Archaeology and Epigraphy 23/2: 145-155.

Nadel, D., Bar-Oz, G., Avner, U., Boaretto, E. \& Malkinson, D. 2010. Walls, ramps and pits: the construction of the Samar Desert kites, southern Negev, Israel. Antiquity 84/326: 976-992.

Nadel, D., Bar-Oz, G., Avner, U., Malkinson, D. \& Boaretto, E. 2013. Ramparts and walls: building techniques of kites in the Negev Highland. Quaternary International 297: 147-154.

Zaninetti, J.-M. 2005. Statistique spatiale, méthodes et applications géomatiques. Paris: Lavoisier.

Zeder, M., Bar-Oz, G., Rufolo, S. \& Hole, F. 2013. New perspectives on the use of kites in mass-kills of Levantine gazelle: a view from northeastern Syria. Quaternary International 297: 110-125. 